\title{
Students' perception in the implementation of the IMRaD structure approach and its implications on the research writing process
}

\author{
Tabuena, Almighty C. $\triangle$
}

Espiritu Santo Parochial School of Manila, Inc., Philippines

(almighty.tabuena@gmail.com; almighty.tabuena@esps.edu.ph)

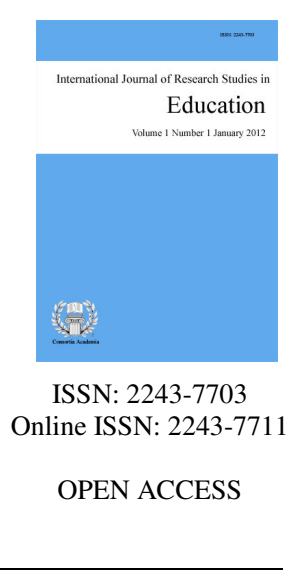

Received: 1 September 2020

Revised: 1 October 2020

Available Online: 11 November 2020

\section{Abstract}

The primary objective of this study is to examine the perceptions of the students regarding the implementation of the IMRaD (Introduction, Methodology, Results, and Discussion) structure approach and its implications on the research writing process. This study used the sequential mixed method design in examining the implementation of the IMRaD format and its implications among Grade 12 senior high school students of the Humanities and Social Sciences strand, conducted at Espiritu Santo Parochial School of Manila, Inc. school year 2019-2020. The developed instrument was reliable using Cronbach's alpha at .926. The data were analyzed by applying descriptive and inferential statistics such as the frequency, weighted mean, average, standard deviation, and independent-sample t-test. The results showed that the students strongly agree in which the approach helped them in terms of the teaching and learning approach, learning tasks, research format writing process, and course outcomes, and interpreted the approach as very effective. The result also showed that there is a significant difference in the grades of students in research courses during the implementation of the IMRaD structure approach. There are implications in terms of the advantages and disadvantages ranging from learning approach, learning process and tasks, content and format, and course outcomes. In general, the IMRaD structure approach will help the students to the vast nature of the research writing process as it is more convenient than the traditional Germanic format research writing method.

Keywords: approach; effects; learning process; research format; research writing method 


\section{Students' perception in the implementation of the IMRaD structure approach and its implications on the research writing process}

\section{Introduction}

Research is globally recognized as a major output of universities and other institutions. On the other hand, the teaching of research methods has received a limited amount of attention (Earley, 2014; Wagner et al., 2011). Much of the institutions teaching on research methods focus more on knowledge transfer while giving little or no attention to context and application of the acquired knowledge (Wagner et al., 2011; Gal \& Ginsburg, 1994). This lack of context makes the learning of research even more difficult for the research naive senior high school students. There is thus a need to look at the teaching of research methods, since equipping the students with these research literacy skills leads to increased research output by the individual (Munabi et al., 2006). As one of the consumers of information generated in institutions, students are a valuable source of feedback leading to quality improvements (Pettersen, 2015; Hill et al., 2003); where the students are the primary emphasis, the perceptions of the students are important in quality monitoring systems which are crucially needed to enable monitoring and evaluation of the important outcomes, the implications on the research writing process.

Since students' research outputs count greatly to research related status of most institutions, then keeping track of students' research-related expectations and performance is a key quality control measure. This in turn will advance on how institutions teach research methods. Cognitive and constructivist theories of learning stress that it is important to understand the learning process from the students' perspective. In the preliminary stage of this classroom-based action research, the researcher found out that the students were having difficulty writing a full research paper in Germanic Format (Chapter 1 as The Problem and Its Background, Chapter 2 as the Review of Related Literature and Studies, Chapter 3 as the Research Methodology, Chapter 4 as the Presentation, Analysis, and Interpretation of Data, and Chapter 5 as the Summary, Conclusion, and Recommendation). In this study, the researcher examined the students' perception in the implementation of the IMRaD structure approach and its implications on the research writing process; one of the formats called as the IMRaD (Introduction, Methodology, Results, and Discussion) structure was used as an approach in teaching research to help the students understand and apply the research concepts in the easiest way of research writing.

The primary objective of this study is to examine the perceptions of the students regarding the implementation of the IMRaD structure approach and its implications on the research writing process. In this situation, the IMRaD structure was used as an approach in teaching research to help the students understand and apply the research concepts in the easiest way of research writing; that is, to identify the implications of the aforementioned structure approach in research writing in terms of its advantages and disadvantages. The result of this classroom-based action research would help the students change their attitude and perception, and freely express their ideas and conceptions in the research writing process.

The IMRaD structure approach has proved successful because it facilitates the literature review, allowing readers to navigate articles more quickly to locate material relevant to their purpose (Burrough-Boenisch, 1999). In addition, it effectively supports a reordering that eliminates unnecessary detail and allows the reader to assess a well-ordered presentation of the relevant and significant information as it allows the most relevant information to be presented clearly and logically to the readership, by summarizing the research process in an ideal sequence and without unnecessary detail. In this situation, as the students embraced the research learning process, they will gradually develop and adopt the specific skills intended for research writing.

Curriculum planners will also be aware of the importance of conducting different research structure approach like the IMRaD format in teaching students' skills related to research in the most feasible way from the traditional Germanic format which is regularly conducted in most universities. The results of this 
Students' perception in the implementation of the IMRaD structure approach on the research writing process

classroom-based action research can help administrators to make plans on how the teachers become aware of the importance of the IMRaD structure approach and its use in planning students' performance-based or output-based tasks. Further, it would help future researchers in discovering other ways of teaching research processes and purposes and would serve as their reference if ever they will conduct a study pertaining to this.

\subsection{Background of the study}

Nowadays, there is an increasing awareness of the importance of research for developing guidelines to direct social and economic interventions (Mason et al., 1999). These guidelines may range from format to format or content to content that involves critical analysis of every solution to a problem using the scientific method in identifying the best evidence-based solution for action at the time. In this case, society expects universities and institutions to lead both the teaching and carrying out of research, and this expectation has led to various policy recommendations and initiatives to promote research and innovation (Oriokot et al., 2011). As to keep pace on the matter, students should be able to write and deliver appropriate reports in research as they would never be complaining about the actual process of research writing. In scientific writing, IMRaD is a common organizational structure (a document format), the most prominent norm for the structure of a scientific journal article of the original research type (Sollaci \& Pereira, 2004) that can be used by the students to help them understand and apply the research concepts in the easiest way of research writing.

According to Meadows (1998), development and changes in the internal organization of the scientific article is simply an answer to the constant growth of information. The IMRaD structure facilitates modular reading because readers usually do not read linearly but browse in each section of the article, looking for specific information, which is normally found in pre-established areas of the paper (Meadows, 1985). In this case, the concept of the IMRaD structure was adopted and used as a teaching tool for the research writing process. As the other disciplines and scientific articles evolved the reporting from letter form and purely descriptive style in the seventeenth century to a very standardized structure in the twentieth century (Sollaci \& Pereira, 2004) known as introduction, methods, results, and discussion (IMRaD), the students' research writing process could also be transformed from a Germanic format of research writing to the IMRaD structure approach. In this method, it would help the students change their attitude and perception, and freely express their ideas and conceptions in the research writing process.

Research education promotes the uniform conduction, interpretation, and response to research findings reported using familiar standard formats of scientific writing. According to Aravamudhan and Frantsve (2009), research education and the adoption of uniform formats of scientific writing promotes evidence-based practice by improving information awareness, seeking, and eventual application of new practices. The rapid increase in the volume of very advanced knowledge and equally rapid changes in the working environment make it increasingly important to equip students with key research skills like scientific writing to keep abreast (Aravamudhan \& Frantsve, 2009; Johnson et al., 2009). This initiative in research education helps the student in establishing and maintaining the research skills with the adoption of the IMRaD structure approach in the research writing process.

There is thus a need to look at the teaching of research methods, since equipping the students with these research literacy skills leads to increased research output by the individual (Munabi et al., 2006). In this case, the perceptions of the students are important in quality monitoring systems which are crucially needed to enable monitoring and evaluation of the important outcomes, the implications of the research writing process. This in turn will advance how institutions teach research methods guided by the cognitive and constructivist theories of learning that emphasize the importance of understanding the learning process from the students' perspective. This would be beneficial to the students to provide them an engaging and conducive learning environment to promote and sustain research endeavors, involvement in research activities strengthens the ties of students to the school they are enrolled in; therefore, academic institutions must enhance such activities for retention purposes (Baker, 2008; Correa, et al., 2015). 
Based on the study of Todorovic (2003), certain rules on how to write original (scientific) papers are pointed out. The structure of all mandatory sections of the paper (i.e. introduction, material and methods, results, and discussion), representing the IMRAD layout is described in detail. Apart from the general rules concerning the preparation of these sections, the importance of following precisely the instructions to authors published by journals is also emphasized. It is important to publish the results of scientific research for many reasons. Some of the reasons could give credibility to the research, inform a broad audience of the achieved scientific results, add credibility to one's reputation, and improve chances for personal promotion. If scientific results were not published and available to a wide scientific audience, it would be as if they had never existed. Today, it is regarded that original (scientific) papers are the only acceptable way of publishing scientific results. A scientific paper is a written and published report describing original research results (Day, 1998).

The IMRaD format is concise and professional to help researchers present their ideas in a heuristic way (Wu, 2011). Implementing IMRaD in scientific writing has a wide range of advantages having a clear structure and standardized framework in writing the results in numerous benefits for both scientific writers and readers. From these reviews, the researcher drew much of the methodology and processes in investigating the perceptions of students regarding the implementation of the IMRaD structure approach to help the students understand and apply the research concepts in the easiest way of research writing and its implications on the research writing process.

\subsection{Statement of the problem}

The primary objective of this study is to examine the perceptions of the students regarding the implementation of the IMRaD structure approach and its implications on the research writing process. To achieve this objective, the study answered the following specific questions:

$>$ What is the perception of the students in the implementation of the IMRaD Structure Approach on the research writing process in terms of the following: teaching and learning approach, learning tasks, research format writing process, and course outcomes?

$>$ Is there a significant difference in the academic performance of the students during the implementation of the IMRaD Structure Approach on the students' research writing process?

D What are the implications in the implementation of the IMRaD Structure Approach on the students' research writing process in terms of its advantages and disadvantages?

\section{Methodology}

This study used the sequential mixed method design in examining the implementation and appraisement of the IMRaD structure approach and its implications on the research writing process among Grade 12 senior high school students of the Humanities and Social Sciences (HumSS) academic strand, conducted at the Espiritu Santo Parochial School of Manila, Inc. in the school year 2019-2020. In terms of data gathering, both quantitative and qualitative methods were implemented in a sequential manner, through survey and interview, respectively. The participants of this study were determined through a stratified proportional random sampling technique, where the number of students in each section was proportioned as to the computed given population in each sample distribution. In the first phase of the sequential mixed method design, in the quantitative method, the research instrument (survey form) was validated by the vice principal for academics and three subject coordinators in the high school department of the Espiritu Santo Parochial School of Manila, Inc., and distributed for the survey process among 17 Grade 12 HumSS students of legal age, the $30 \%$ of the total population of 55 Grade 12 HumSS students; consisting of four parts in terms of teaching and learning approach, learning tasks, research format writing process, and course outcomes. In the second phase, the qualitative method, a structured interview was conducted to expound the data in terms of the implications of the IMRaD structure approach to the research writing process. The researcher collected the data after the validation of the instrument.

58 Consortia Academia Publishing (A partner of Network of Professional Researchers and Educators) 
Students' perception in the implementation of the IMRaD structure approach on the research writing process

The data were analyzed by applying descriptive and inferential statistics; different tests were utilized such as the frequency distribution, weighted mean, mean (average), standard deviation, and independent-sample t-test.

The questionnaire was developed related to the IMRaD structure approach and its implications on the research writing process for data collection. The respondents of the study gave their opinions on a 4-point Likerttype scale from strongly agree to strongly disagree. The validity and reliability of the instrument were measured by pilot testing. Experts validated the questionnaire by highlighting the strong and weak areas. After validation, reliability was calculated.

Table 1 shows the reliability of the research instrument. The questionnaire contained twenty statements (items) about the students' perception of the implementation of the IMRaD structure approach and its implications on the research writing process. The Cronbach's Alpha was applied to check the reliability of the instrument. The questionnaire has 20 items with a 4-point Likert scale for every item. The null hypothesis is set the coefficient of Cronbach's alpha $(\mathrm{CA} 0)$ at .50 while in the alternative hypothesis; the coefficient of Cronbach's alpha (CA1) is set at 90 . Based on an alpha of .05, the minimum sample size requirement is 11 to be able to detect at least $90.0 \%$ power of the test. The calculation is based on the formula introduced by Bonett- 6 (Bonnett \& Wright, 2015). The instrument's reliability of 20 items was .926 inferred to an excellent internal consistency.

Table 1

Reliability of the instrument

\begin{tabular}{lccc}
\hline Items & Cronbach's Alpha & No. of Items & Internal Consistency \\
\hline Teaching and Learning Approach & .787 & 5 & Acceptable \\
Learning Tasks & .795 & 5 & Acceptable \\
Research Format Writing Process & .796 & 5 & Acceptable \\
Course Outcomes & .858 & 5 & Good \\
$\quad$ Research Instrument & .926 & 20 & Excellent \\
\hline
\end{tabular}

\section{Results and discussion}

\subsection{Students' perception in the implementation of the IMRaD structure approach to the research writing process}

Teaching and learning approach - According to the gathered data among the students, they strongly agree that the IMRaD structure approach helped them in terms of the teaching and learning approach with an average weighted mean of 3.51, interpreted as very effective on the research writing process. The students are able to interact with the classroom activities (classroom activities and interaction), to learn more (motivation), to prepare with the requirements (i.e. research paper, documents) before turning it in (preparation), to understand on how to apply the research skills and its functions in the research writing process in the course (practice tests), and to understand the course with the help of the visual aids and presentations in accordance with the approach.

Table 2

Response on the teaching and learning approach of the students

\begin{tabular}{|c|c|c|c|}
\hline Indicators & Weighted Mean & Perception & Interpretation \\
\hline Classroom Activities and Interaction & 3.59 & Strongly Agree & Very Effective \\
\hline Motivation & 3.59 & Strongly Agree & Very Effective \\
\hline Preparation & 3.29 & Strongly Agree & Very Effective \\
\hline Practice Tests & 3.35 & Strongly Agree & Very Effective \\
\hline Visual Aids and Presentations & 3.71 & Strongly Agree & Very Effective \\
\hline Average & 3.51 & Strongly Agree & Very Effective \\
\hline
\end{tabular}

Learning tasks - In terms of the learning tasks (written tasks, mini and major performance tasks, and quarterly assessment), the students strongly agree that the IMRaD structure approach helped them in the research 
writing process with an average weighted mean of 3.28, interpreted as very effective. The students are able to apply the specific learning tasks based on an essential, academic standard, and has a clear outcome in terms of student performance (specific), to have multiple measures, both summative and formative, used ongoing to monitor progress and make adjustments to instruction (measurable), to undergo a reasonable time frame and reference targeted instruction, assessment, and intervention connected to the objective of the course (realistic but significant improvement will result from working toward the learning tasks; attainable), to acquire specific levels of expected performance tied to an important content standard, and that represent important and meaningful learning for all students (result-oriented), and to have a sufficient time frame (Schedule of Learning Activities) which specifically identified and linked to each learning task (time-bound).

Table 3

Response to the learning tasks of the students

\begin{tabular}{|c|c|c|c|c|}
\hline Indicators & & Weighted Mean & Perception & Interpretation \\
\hline Specific & & 3.41 & Strongly Agree & Very Effective \\
\hline Measurable & & 3.41 & Strongly Agree & Very Effective \\
\hline Attainable & & 3.12 & Agree & Effective \\
\hline Result-Oriented & & 3.12 & Agree & Effective \\
\hline Time-Bound & & 3.35 & Strongly Agree & Very Effective \\
\hline & Average & 3.28 & Strongly Agree & Very Effective \\
\hline
\end{tabular}

Research format writing process - The students strongly agree that the IMRaD structure approach helped them in terms of the format of the research writing process with an average weighted mean of 3.65, interpreted as very effective. The IMRaD format is appropriate, essential, has an academic standard, and clear outcome in terms of student performance in the research writing process (specific), it suggests an indicator of progress in terms of research writing (measurable), it has a reasonable time frame and reference targeted instruction, assessment, and intervention connected to the objective of the course (attainable), it is applicable for the research method and outcome in the research writing process (result-oriented), and the materials (requirements and IMRaD documents) of the course were suitable for its period; time frames are specifically identified and linked to each component of the IMRaD structure (time-bound).

\section{Table 4}

Response to the research format writing process of the students

\begin{tabular}{lcll}
\hline \multicolumn{1}{c}{ Indicators } & Weighted Mean & Perception & Interpretation \\
\hline Specific & 3.59 & Strongly Agree & Very Effective \\
Measurable & 3.76 & Strongly Agree & Very Effective \\
Attainable & 3.71 & Strongly Agree & Very Effective \\
Result-Oriented & 3.65 & Strongly Agree & Very Effective \\
Time-Bound & 3.53 & Strongly Agree & Very Effective \\
& & Strongly Agree & Very Effective \\
\hline
\end{tabular}

Course outcomes - The students also strongly agree that the IMRaD structure approach helped them in terms of the course outcomes on the research writing process with an average weighted mean of 3.37, interpreted as very effective. For the Practical Research 2 course, the students are able to establish an understanding of the range of research topics in the area of inquiry, the value of research in the area of interest, and the specificity of the problem posed through research outline proposal and concept paper writing (course outcome 1); to describe adequately quantitative research designs, sample, an instrument used, data collection and analysis procedures, and gather and analyze data with intellectual honesty, using suitable statistical and non-statistical techniques through title defense (course outcome 2); to demonstrate an understanding of the importance of research in daily life; the characteristics, processes, and ethics of research; mostly concern on the quantitative analysis and different statistical tools through the development of research instrument in terms of validity and reliability (course outcome 3). For the Inquiries, Investigations and Immersion course, they are able to describe adequately quantitative research designs, sample, an instrument used, data collection and analysis procedures, and gather

60 Consortia Academia Publishing (A partner of Network of Professional Researchers and Educators) 
Students' perception in the implementation of the IMRaD structure approach on the research writing process and analyze data with intellectual honesty, using suitable statistical and non-statistical techniques through a written manuscript and defense (course outcome 4), and to form logical and valid conclusions in making recommendations based on conclusions, and write and present clear report (course outcome 5).

Table 5

Response on the course outcomes of the students

\begin{tabular}{|c|c|c|c|c|}
\hline Indicators & & Weighted Mean & Perception & Interpretation \\
\hline Course Outcome 1 & & 3.41 & Strongly Agree & Very Effective \\
\hline Course Outcome 2 & & 3.24 & Agree & Effective \\
\hline Course Outcome 3 & & 3.53 & Strongly Agree & Very Effective \\
\hline Course Outcome 4 & & 3.24 & Agree & Effective \\
\hline Course Outcome 5 & & 3.41 & Strongly Agree & Very Effective \\
\hline & Average & 3.37 & Strongly Agree & Very Effective \\
\hline
\end{tabular}

Summary - The students also strongly agree that the IMRaD structure approach helped them in terms of the course outcomes on the research writing process with an average weighted mean of 3.37, interpreted as very effective. For the Practical Research 2 course, the students are able to establish an understanding of the range of research topics in the area of inquiry, the value of research in the area of interest, and the specificity of the problem posed through research outline proposal and concept paper writing; to describe adequately quantitative research designs, sample, an instrument used, data collection and analysis procedures, and gather and analyze data with intellectual honesty, using suitable statistical and non-statistical techniques through title defense; to demonstrate an understanding of the importance of research in daily life; the characteristics, processes, and ethics of research; mostly concern on the quantitative analysis and different statistical tools through the development of research instrument in terms of validity and reliability. For the Inquiries, Investigations and Immersion course, they are able to describe adequately quantitative research designs, sample, an instrument used, data collection and analysis procedures, and gather and analyze data with intellectual honesty, using suitable statistical and non-statistical techniques through a written manuscript and defense, and to form logical and valid conclusions in making recommendations based on conclusions, and write and present clear report.

In general, the students strongly agree that the IMRaD structure approach helped them in terms of the teaching and learning approach, learning tasks, research format writing process, and course outcomes on the research writing process with a general average weighted mean of 3.45, interpreted as very effective.

Table 6

Summary response on the implementation of the IMRaD structure approach of the students

\begin{tabular}{|c|c|c|c|}
\hline Indicators & Average Weighted Mean & Perception & Interpretation \\
\hline Teaching and Learning Approach & 3.51 & Strongly Agree & Very Effective \\
\hline Learning Tasks & 3.28 & Strongly Agree & Very Effective \\
\hline Research Format Writing Process & 3.65 & Strongly Agree & Very Effective \\
\hline Course Outcomes & 3.37 & Strongly Agree & Very Effective \\
\hline General Average & 3.45 & Strongly Agree & Very Effective \\
\hline
\end{tabular}

\subsection{Significant difference between the grades of the students}

The value of $t$ of -3.745 is significant at $p<.01$. The result showed that there is a significant difference in the grades of students in research courses between Practical Research 2 and Inquiries, Investigations, and Immersion during the implementation of the IMRaD structure approach on the research writing process. The mean difference was 4.12. In addition, the computed $t$ is greater than the tabular $t$ of 2.583 , thus the hypothesis of no difference in the mean grades of the students in the specified research courses during the implementation of the IMRaD structure approach is rejected. Therefore, the IMRaD structure approach is effective as a tool for the research writing process. 
Tabuena, A. C.

Table 7

Significant difference between the grades of the students

\begin{tabular}{ccccccc}
\hline Variables & Mean & $S D$ & $\begin{array}{c}\text { Mean } \\
\text { Difference }\end{array}$ & $t$-value & $\begin{array}{c}\text { Significant } \\
\text { Value }\end{array}$ & Decision $\mathrm{H}_{\mathrm{o}}$ \\
\hline Course $1^{\mathrm{a}}$ & 87.76 & 3.63 & 4.12 & -3.745 & 2.583 & Rejected \\
Course $2^{\mathrm{b}}$ & 91.88 & 2.71 & & &
\end{tabular}

\subsection{Implications of the IMRaD structure approach in the research writing process}

Advantages of the IMRaD structure approach in the research writing process - The most common response of the students in the implementation of the IMRaD structure approach is the organization, straightforward, and ease of use of writing research as they can easily understand and learn the topic and the details of the research writing process.

According to the interview among the students, one of the advantages of the IMRaD structure approach in the research writing process is its SMART characteristics: specific, measurable, attainable, results-oriented, and time-bound. In this way, it is a more achievable and time-bounded approach compared to the traditional approach, the Germanic format. The IMRaD structure approach also improves one of the skills in the research process as it enhances both skimming and scanning skills in reading to locate specific information without reading the entire article, as part of the literature review process. As it helps the students to accomplish the process of inquiry to an investigation, presentation to a discussion, students were able to look at research writing process as simple as possible since it tries to make it look more comprehensible focusing the most essential parts of research, by completing the research paper in the most relevant, effective and fastest way within a limited period.

In learning the IMRaD structure, as the students prepare for the paper, it can help them to organize and clearly understand what their study will be; as they are not distracted by the long format and guidelines of research writing. It is easier for them to execute the entire research process, giving them clear guidelines about the objectives, and assisting them to find relevant and accurate information or data needed in their research paper. Further, in terms of the content, IMRaD is more condensed and compact, making it shorter but more concise than the traditional writing approach. As it is shorter than the usual structure, student-researchers can think and focus more on the important contents of their research; recommended for the new researchers to be able to easily read and comprehend than the usual Germanic structure as they learn simultaneously the process and the practical application of research writing.

Disadvantages of the IMRaD structure approach in the research writing process - Students perceived and criticized the IMRaD structure approach as too rigid and simple in which it may not give a realistic representation of the thought processes of a research paper. Most of them think that it lacks detail representation of the processes in research writing - parts may not be explained thoroughly, traditional research may not be practiced, shortness of the paper's process may disregard its potential to compete into the full-length research approach and may look invalid, information and skills may overlook that must be taught to the students immediately, details may be missed due to the congestion of information, and people who are used to the old process of doing research may find it hard to adjust using the IMRaD structure. Further, the IMRaD structure approach is time-consuming and a bit advanced for some students. The readers may misinterpret some ideas from the article if the words used are confusing. Sometimes, some of the research may not apply using the format because of the long term in studying the research, the outcome of the research may not be the final result. In terms of data gathering, minimal but important information may be left out from a study if the researcher would be pressured in limiting gathered data. In terms of the content, the structure needs to be precise at all times and there is a possibility of lacking some key concepts because of the format. 
Students' perception in the implementation of the IMRaD structure approach on the research writing process

General effects of the IMRaD structure approach in the research writing process - In general, the IMRaD structure approach on the research writing process has proven effective as it encourages analysis of the literature, enables readers to search articles faster, finds material relevant to their intent, prioritizes certain information, gives more accurate information and details about the research, navigates pivotal data while focusing on key concepts - its efficiency regarding the scope, limitations, and delimitations of the research study, saves time and helps to be more clear in what the researchers want to say, and makes the research writing easier. In addition to the interview among the students, this approach will help in introducing or orienting the students to the vast nature of the research writing process. It is more convenient for the researcher than the traditional research writing method.

\subsection{Discussion}

The IMRaD structure approach helped the students in terms of the teaching and learning approach, learning tasks, research format writing process, and course outcomes on the research writing process. In this way, it is a more achievable, time-bounded, and convenient approach for the researcher than the traditional research writing method, the Germanic format. It also improves one of the skills in the research process as it enhances both skimming and scanning skills in reading to locate specific information without reading the entire article, as part of the literature review process. Learning to scan for information in research articles is an important skill for students in the field of research. In this process, this would be beneficial to the students to provide them an engaging and conducive learning environment to promote and sustain research endeavors as stated by Baker (2008) and Correa et al. (2015). A clear understanding of these functions is important in developing effective research strategies that would help students change their attitude and perception, and freely express their ideas and conceptions in the research writing process.

As specified by Munabi et al. (2006), there is a need to look at the teaching of research methods, since equipping the students with research literacy skills leads to increased research output by the individual; this IMRaD structure approach helps the students understand and apply the research concepts in the easiest way of research writing and gives various positive implications on the research writing process. According to Gensee and Upshur (1996), to plan and make instruction that is appropriate for individual students or groups of students, it is necessary to understand the factors that influence student performance in class. Chastain (1988) believes that teachers need to evaluate constantly their teaching based on student reaction, interest, motivation, preparation, participation, perseverance, and achievement. The conclusions drawn from such an assessment or appraisement constitute their main source for measuring the effectiveness of selected learning activities. Thus, the IMRaD structure approach will help the students in familiarizing themselves with the vast nature of the research writing process as they simultaneously learn the process and the practical application of research writing.

\section{Conclusion}

The students strongly agree that the IMRaD structure approach helped them in terms of the teaching and learning approach, learning tasks, research format writing process, and course outcomes on the research writing process as very effective. The t-ratio showed that there is a significant difference in the grades of students in research courses between Practical Research 2 and Inquiries, Investigations, and Immersion during the implementation of the IMRaD structure approach on the research writing process. In addition, the computed t-ratio is greater than the tabular t-value thus the hypothesis of no difference in the mean grades of the students in the specified research courses during the implementation of the IMRaD structure approach is rejected. Therefore, the IMRaD structure approach is effective as a tool for the research writing process. There are implications in terms of the advantages and disadvantages ranging from learning approach, learning process and tasks, content and format, and course outcomes. In general, the IMRaD structure approach on the research writing process has proven effective as it encourages analysis of the literature, enables readers to search articles faster, finds material relevant to their intent, prioritizes certain information, gives more accurate information and details about the research, navigates pivotal data while focusing on key concepts - its efficiency regarding the scope, limitations, 
and delimitations of the research study, saves time and helps to be more clear in what the researchers want to say, and makes the research writing easier. In addition to the interview among the students, this approach will help in introducing or orienting the students to the vast nature of the research writing process. It is more convenient for the researcher than the traditional research writing method.

\subsection{Recommendations}

The following are the recommendations of the researcher to further improve the research program, particularly in the research courses for the senior high school: further implementation and assessment of the IMRaD structure approach for the research courses; sustain or improve the teaching and learning approach in terms of classroom activities and interaction, motivation, preparation, practice tests, visual aids and presentations, and the learning tasks in terms of written tasks, mini and major performance tasks, and quarterly assessment; and further research development program for the students.

\section{References}

Aravamudhan, K., \& Frantsve-Hawley, J. (2009). American dental association's resources to support evidence-based dentistry. The Journal of Evidence-based Dental Practice, 9(3), 139-144. https://doi.org/10.1016/j.jebdp.2009.06.011

Baker, C. N. (2008). Under-represented college students and extracurricular involvement: The effects of various student organizations on academic performance. Social Psychology of Education, 11, 273-298. https://doi.org/10.1007/s11218-007-9050-y

Bonett D. G., \& Wright, T. A. (2015). Cronbach's alpha reliability: interval estimation, hypothesis testing, and sample size planning. Journal of Organizational Behavior, 36(1), 3-15. https://doi.org/10.1002/job.1960

Burrough-Boenisch, J. (1999). International reading strategies for IMRD articles. Written Communication, 16(3), 296-316. https://doi.org/10.1177/0741088399016003002

Chastain, K. (1988). Developing second language skills. Florida: Harcourt Brace Jovanovich.

Correa, M., Dumas, B. K., Jones, C., Mbarika, V., \& Ong'oa, I. M. (2015). Extracurricular activities and academic achievement: A literature review. Global Advanced Research Journal of Educational Research and Review, 4(9), 165-169.

Day, R. A. (1998). How to write and publish a scientific paper (5th ed.). Phoenix: The Oryx Press. https://doi.org/10.1590/S0074-02761998000300029

Earley, M. A. (2014). A synthesis of the literature on research methods education. Teaching in Higher Education, 19(3), 242-253. https://doi.org/10.1080/13562517.2013.860105

Gal, I., \& Ginsburg, L. (1994). The role of beliefs and attitudes in learning statistics: Towards an assessment framework. Journal of Statistics Education, 2(2). https://doi.org/10.1080/10691898.1994.11910471

Genesee, F., \& Upshur, J. (1996). Classroom-based evaluation in second language education. Cambridge: Cambridge University Press.

Hill, Y., Lomas, L., \& MacGregor, J. (2003). Students' perceptions of quality in higher education. Quality Assurance in Education, 11(1), 15-20. https://doi.org/10.1108/09684880310462047

Johnson, N., List-Ivankovic, J., Eboh, W. O., Ireland, J., Adams, D., Mowatt, E., \& Martindale, S. (2009). Research and evidence based practice: Using a blended approach to teaching and learning in undergraduate nurse education. Nurse Education in Practice, 10, 43-47. https://doi.org/10.1016/j.nepr.2009.03.012

Mason, J., Eccles, M., Freemantle, N., \& Drummond, M. (1999). Incorporating economic analysis in evidence-based, guidelines for mental health: the profile approach. The Journal of Mental Health Policy and Economics, 2(1), 13-19. https://doi.org/10.1002/(SICI)1099-176X(199903)2:1<13::AID-MHP34>3.0.CO;2-M

Meadows, A. J. (1985). The scientific paper as an archaeological artifact. Journal of Information Science, 11(1), 27-30. https://doi.org/10.1177/016555158501100104 
Meadows, A. J. (1998). Communicating research. San Diego, CA: Academic Press.

Munabi, I. G., Katabira, E. T., \& Konde-Lule, J. (2006). Early undergraduate research experience at Makerere University Faculty of Medicine: A tool for promoting medical research. African Health Sciences, 6(3), 182-186.

Oriokot, L., Buwembo, W., Munabi, I. G., \& Kijjambu, S. C. (2011). The introduction, methods, results and discussion (IMRAD) structure: A survey of its use in different authoring partnerships in a students' journal. BMC Research Notes, 4, 250. https://doi.org/10.1186/1756-0500-4-250

Pettersen, I. J. (2015). From metrics to knowledge? quality assessment in higher education. Financial Accountability \& Management, 31(1), 23-40. https://doi.org/10.1111/faam.12048

Sollaci, L., \& Pereira, M. (2004). The introduction, methods, results, and discussion (IMRAD) structure: a fifty-year survey. Journal of the Medical Library Association, 92(3), 364-371.

Subong, P. E., Jr. (2005). Statistics for research. Manila: Rex Book Store, Inc.

Todorovic, L. (2003). Original (scientific) paper - the IMRAD layout. Archive of Oncology, 11(3), 203-205. https://doi.org/10.2298/AOO0303203T

Wagner, C., Garner, M., \& Kawulich, B. (2011). The state of the art of teaching research methods in the social sciences: Towards a pedagogical culture. Studies in Higher Education, 36(1), 75-88. https://doi.org/10.1080/03075070903452594

Wu, J. (2011). Improving the writing of research papers: IMRAD and beyond. Landscape Ecology, 26(10), 1345-1349. https://doi.org/10.1007/s10980-011-9674-3 
Tabuena, A. C. 